\title{
Anesthesia-Related Mortality in Children: A Surgeon's Perspective
}

\author{
Chukwubuike Kevin Emeka \\ Faculty Pediatric Surgery Unit, Department of Surgery, Enugu State University Teaching Hospital, Enugu, \\ Nigeria \\ chukwubuikeonline@yahoo.com
}

\begin{abstract}
Background: Anesthesia-related mortality refers to death resulting from the complications of anesthesia or death due to at least one anesthesia-related complication happening as a cause among the multiple causes of death. The aim of this study was to evaluate the incidence and causes of anesthesia-related mortality in pediatric patients, as experienced by a surgeon. Materials and Methods: This was a retrospective study of children aged 15 years and younger who died at the pediatric surgery unit of Enugu State University Teaching Hospital (ESUTH) Enugu, Nigeria following administration of anesthesia between January 2010 and December 2019. Results: A total of 31,210 pediatric anesthesias/surgeries were performed during the study period; out of which 78 mortalities occurred due to anesthesia. There was male predominance and the median age of the patients was 4 years with a range of 1 week to 12 years. Mortality occurred more in neonates and during emergency surgeries. Airway complications and intussusception were the most common etiology of mortality and pathology in the children respectively. About two-thirds of the deaths occurred in the operating room before commencement of the surgery. Conclusion: Anesthesia-related deaths in children in middle income country like Nigeria are higher than what is obtainable in developed countries. The risk factors for anesthesia-related mortality include male gender, neonates and emergency surgeries. Airway problem is a common cause of mortality.
\end{abstract}

Keywords: anesthesia; mortality; children

\section{Introduction}

Anesthesia-related mortality refers to death resulting from the complications of anesthesia or death due to at least one anesthesia-related complication happening as a cause among the multiple causes of death [1]. Such complications include pulmonary, cardiac, central nervous system complications, failed or difficult intubation, overdose or adverse effect of anesthetic drugs [1]. Tudjegbe et al defined anesthetic death as the death of a patient who has had an anesthetic, within 24 hours of the procedure [2]. However, it is important to note that there is no consensus in the literature regarding the definition of anesthesia-related mortality [3]. Attributing death to anesthesia is difficult and is often subjective [4]. The Australian and New Zealand College of Anesthetists Mortality Committee classified anesthesia-related mortality into 3 categories: Category 1: Cases in which it is reasonably certain that death was caused by anesthesia or other factors under the control of the anesthetist. Category 2 is used when there is some doubt as to whether death was entirely attributable to the anesthesia or other factors under the control of the anesthetist. Category 3 applies when death was caused by both surgical and anesthetic factors [5]. Insight into the contribution of anesthesia to peri-operative mortality is important to both the anesthetists and surgeons. Data from anesthesia-related mortality will enable further improvements in the safety and quality of peri-operative care [6]. Evaluation of anesthesia-related mortality provides knowledge on the quality of anesthetic management, allowing preventive measures to be instituted [6]. Analysis of anesthesia- 
related mortality helps to determine which children are at higher risk and guide planning to improve safety of the children [1]. The aim of this study was to evaluate the incidence and causes of anesthesia-related mortality in pediatric patients, as evaluated by a surgeon.

\section{Research Methods}

This was a retrospective study of children aged 15 years and younger who died at Enugu State University Teaching Hospital (ESUTH) Enugu, Nigeria following administration of anesthesia in theatre between January 2010 and December 2019. Children who died in the ward or in theatre before administration of anesthesia were excluded from the study. For the purposes of this study, children who died after 24 hours of surgery were also excluded. ESUTH is a tertiary hospital located in Enugu, South East Nigeria. The hospital serves the whole of Enugu State, which according to the 2016 estimates of the National Population Commission and Nigerian National Bureau of Statistics, has a population of about 4 million people and a population density of $616.0 / \mathrm{km} 2$. The hospital also receives referrals from its neighboring states. Information was extracted from the case notes, operation notes, and operation register and admissiondischarge records. The information extracted included the age, gender, and pathology necessitating surgery, duration of symptoms before presentation, time interval between presentation and intervention, nature of the surgery (emergency/elective), possible anesthetic cause of death, operative procedure performed, and time (preoperative/postoperative) of mortality. Diagnosis of clinical death was based on the absence of respiratory efforts, no cardiac activity and dilated, fixed and non-reactive pupils. The follow-up period was 12 months. Ethical approval was obtained from the ethics and research committee of ESUTH and informed consent was obtained from the patients' caregivers. Statistical Package for Social Science (SPSS) version 21 (manufactured by IBM Corporation Chicago Illinois) was used for data entry and analysis. Data were expressed as percentages, median, mean, and range.

\section{Discussion}

\subsection{Results}

\section{a. Patients' Demographics}

Eighty-three cases of pediatric anesthetic mortalities occurred during the study period but only 78 cases had complete case records and formed the basis of this report. A total of 31,210 pediatric anesthesia/surgeries were performed during the same period: This gives an anesthetic mortality rate of $0.25 \%$. Details of the demographics are shown in Table 1 .

Table 1. Demographic Profile of the Patients $(n=78)$

Gender

Male

$58(74.4 \%)$

Female

$20(25.6 \%)$

Age range

1 week to 12 years (median 4 years) 
Age groups

$$
\begin{array}{lc}
\text { Neonates }(<1 \text { month }) & 41(52.6 \%) \\
\text { Infants }(1-12 \text { months }) & 21(26.9 \%) \\
12 \text { months to } 11 \text { years } & 16(20.5 \%)
\end{array}
$$

Nature of the surgery

$$
\begin{array}{lc}
\text { Emergency } & 61(78.2 \%) \\
\text { Elective } & 17(21.8 \%)
\end{array}
$$

Mean interval from symptoms to presentation 2 to 10 days (median 7 days) Mean interval from presentation to surgery 2 days (1-3)

\section{b. Pathology Involved and Operative Procedure Performed (n=78)}

Table 2. The Different Pathologies that Necessitated Operative Treatment

\begin{tabular}{|llc|}
\hline Pathology & Operative procedure & Number of patients (\%) \\
\hline Intussusception & RHC with ITA & $36(46.2)$ \\
Typhoid intestinal obstruction & Closure of perforation & $27(34.6)$ \\
Neonatal intestinal obstruction & Resection and anastomosis & $7(8.9)$ \\
Ruptured appendix & Abscess drainage & $3(3.8)$ \\
Obstructed inguinal hernia & Herniotomy & $2(2.6)$ \\
Adhesive intestinal obstruction & Adhesiolysis & $2(2.6)$ \\
Ruptured spleen & Splenectomy & $1(1.3)$ \\
\hline
\end{tabular}

RHC=Right hemicolectomy; ITA=Ileotrans verse anastomosis

\section{c. Possible Anesthetic Cause of Death}

The cause of mortality is illustrated in Table

Table 3. Causes of Mortality

\begin{tabular}{|lc|}
\hline Causes of mortality & Number of patients (\%) \\
\hline Airway complications & $41(52.6)$
\end{tabular}




\begin{tabular}{lc}
\hline Respiratory complications & $21(26.9)$ \\
Cardiac complications & $11(14.1)$ \\
Adverse reaction to anesthetics & $3(3.8)$ \\
Central nervous system complications & $2(2.6)$
\end{tabular}

\section{d. Period (Preoperative/Postoperative) of Mortality}

Fifty-one $(65.4 \%)$ patients died in theatre (before commencement of the surgery), 16 (20.5\%) children expired intra-op and $11(14.1 \%)$ died post-op.

\subsection{Discussion}

Anesthesia-related mortality pertains to patients who died for whom anesthesiarelated factor was identified and who it was judged would not have died if he/she had not undergone the procedure [6]. These anesthetic factors could be preventable or nonpreventable [6]. Anesthesia is often regarded a high risk intervention: However, in the past 2 decades, anesthesia-related mortality has decreased due to improvements in techniques and monitoring [7]. It is noteworthy to state that the definition of death in which anesthesia was the primary cause or a contributing cause varies widely among the investigators [4].

In the present study, the anesthesia-related mortality rate recorded in the present study is at variance to the reports of other authors [3, 8]. Unlike in developing countries, there have significant decrease in the rate of anesthesia-related mortality in developed countries [9]. Dearth of facilities and low human development index seen in developing countries may account for the differences in the rates of anesthesia-related mortality [10]. This study recorded more deaths in males than females. This finding is consistent with the report of $\mathrm{Li}$ et al and Pascal et al [1,11]. However, Argo et al found more anesthetic deaths in females [12]. The reason for the gender differences in anesthetic deaths is not known. The age range of children who had anesthesia-related mortality varies depending on the predominant pathology. For instance, intussusception is more likely to occur in infants. About half of the anesthesia-related mortality in the index study occurred in neonates. Disma et al also reported more mortality in neonates [12]. The reason for this may be because the fragile homeostasis of the neonate is adversely affected by the stress of surgery and anesthesia [14]. Emergency surgeries are fraught with complications and we found more anesthesia-related deaths in emergency surgeries. Other series also reported higher anesthesia-related mortalities on emergency cases [4, 15]. Full stomach, poor patients' preparations and non-availability of experienced hands during emergency situations may explain the higher anesthesia-related deaths. Delayed presentation of the patients is evident in the mean 7-day lag period. Poverty and ignorance that is prevalent in low income countries may explain this delayed presentation. The mean interval of 2 days was the time required for the investigation, resuscitation and optimization of the patients before surgery.

About one-half of the children who lost their lives following the administration of anesthesia had intussusception. One study from Tanzania also found significant mortality in children with intussusception [16]. Typhoid intestinal perforation was the second most common pathology in the patients. Typhoid fever, caused by gram-negative flagellated facultative anaerobic bacteria (Salmonella), is a common problem in developing countries due to lack of potable drinking water, poor hygiene and improper waste disposal [17]. 
Inability to secure the airway, difficult or failed intubation, following administration of anesthetic drugs was the most common cause of mortality in the current study. One study from Brazil also reported airway management as a common cause of anestheticrelated death in pediatric patients [4]. Airway problems encountered include complications of endotracheal intubation such as esophageal intubation or delays in intubation as seen in inexperienced anesthetists [12]. The most common of the endotracheal mishaps is unsuccessful intubation after muscle relaxant administration [18]. Other causes of airway problems are disconnection, dislodgement of the endotracheal tube, tube kinking, tube obstruction, bronchospasm, aspiration of vomitus and anatomic abnormalities [12]. The sequel of failed intubation is hypoxic-ischemic encephalopathy and brain death due to oxygen deficiency [19]. Side effect of anesthetic drugs such as malignant hyperthermia may also be a cause of anesthetic death in theatre [20].

Majority of the patients in the current study died in theatre. Morray et al also reported higher mortality in the operating room [21].

\section{Conclusion}

Anesthesia-related deaths in children in low/middle income country like Nigeria are higher than what is obtainable in developed countries. The risk factors for anesthesiarelated mortality include male gender, neonates and emergency surgeries. Airway problem is a common cause of mortality. This data on anesthesia-related mortality may be useful in promulgating prevention strategies to reduce mortalities in children.

\section{Limitations of the Study}

1. Autopsy was not done because of parents/caregivers' refusal.

2. American Society of Anesthesiologist (ASA) physical status classification system was not done.

\section{References}

1. Li G, Warner M, Lang BH, Huang L, Sun LS. Epidemiology of anesthesia-related mortality in United States, 1999-2005. Anesthesiology. 2009; 110(4): 759-765

2. Tudjegbe SO, Amadasun FE. What is anesthetic death? Annals of Biomedical Sciences. 2010; 9(1): 1-6

3. Deshpande JK. Cause and effect or conjecture? A call for consensus on defining "anesthesia-related mortality" Anesth Analg. 2011;112(6): 1259-1261

4. Gonzalez LP, Pignaton W, Kusano PS, Modolo NS, Braz LG. Anesthesia-related mortality in pediatric patients: a systemic review. Clinics (Sao Paulo). 2012; 67(4): 381-387

5. Gibbs NM. National Anaesthesia Mortality Reporting in Australia from 1985-2008. Anaesthesia and Intensive Care. 2013; 41(3): 294-301

6. Arbous MS, Grobbee DE, van Kleef JW, de Lange JJ, Spoormans HH, Touw P et al. Mortality associated with anaesthesia: a quantitative analysis to identify risk factors. Anaesthesia. 2001; 56(12): 1141-1141

7. Lienhart A, Auroy Y, Pequignot F, Benhamou D, Warszawski J, Bovet M. et al. Survey of anesthesia-related mortality in France. Anesthesiology. 2006; 105(6): 1087-1097

8. Biboulet P, Aubas P, Dubourdieu J, Rubenovitch J, Capdevila, d'Athis et al. Fatal and non-fatal cardiac arrests related to anesthesia. Can J Anaesth. 2001; 48(4): 326-332

9. Bharati SJ, Chowdhury T, Gupta N, Schaller B, Cappellani RB, Maguire D. Anesthesia 
in underdeveloped world. Present scenario and future challenges. Niger Med J. 2014; 55(1): $1-8$

10. Walker AI, Wilson IH. Anaesthesia in developing countries-a risk for patients. Lancet. 2008; 22: 371(9617)968-969.

11. Pascal FNB, Malisawa A, Barratt-Due A, Namboya F, Pollach G. General anaesthesia related mortality in a limited resource settings region: a retrospective study in two teaching hospitals of Butembo. BMC Anesthesiology. 2021;21: 60

12. Argo A, Zerbo S, Lanzarone A, Buscemi R, Roccuzzo R, Karch SB. Perioperative and anesthesia deaths: toxicological and medico legal aspects. Egypt J Forensic Sci. 2019; 9: 20

13. Disma N, Veyckemans F, Virag K, Hansen TG, Becke K, Harlet P et al. Morbidity and mortality after anaesthesia in early life: results of European prospective multicenter observational study, neonate and children. audit of anaesthesia practice in Europe. 2021; 126(6): 1157-1172

14. Chukwubuike KE. Challenges and Outcome of Neonatal Surgeries in a Teaching Hospital in Enugu, Nigeria. Rwanda Medical Journal. 2021; 78(1): 52-58

15. de Bruin L, Pasma W, van der Werff DB, Schouten TA, Haas F, van der Zee DC et al. Perioperative hospital mortality at a tertiary paediatric institution. $\mathrm{Br} \mathrm{J}$ Anaesth. 2015; 115(4): 608-615

16. Chalya PL, Kayange NM, Chandika AB. Childhood intussusceptions at a tertiary care hospital in northwestern Tanzania: a diagnostic and therapeutic challenge in resource-limited setting. Ital J Pediatr. 2014; 40(1): 28.

17. Chukwubuike KE. Typhoid intestinal perforation in children. Still a persistent problem in a developing country. Clin Surg Res Commun. 2020; 4(2): 26-31

18. Auroy Y, Benhamou D, Pequignot F, Bovet M, Jougla E, Lienhart A. Mortality related to anaesthesia in France: Analysis of deaths related to airway complications. Anaesthesia. 2009; 64(4): 366-370

19. Cook TM, MacDougall-Davis SR. Complications and failure of airway management. Br J Anaesth. 2012; 109 Suppl 1: i68-i85.

20. Anetseder M, Hager M, Muller CR, Roewer N. Diagnosis of susceptibility to malignant hyperthermia by use of a metabolic test. Lancet. 2002; 359(9317): 15791580

20. Morray JP, Geiduscheck JM, Ramamoorthy C, Haberkern CM, Hackel A, Caplan RA et al. Anesthesia-related cardiac arrest in children: initial findings of the Pediatric Perioperative Cardiac Arrest (POCA) Registry. Anesthesiology. 2000; 93(1): 6-14 